\title{
Too high radon risks not helped by “penny-pinching” UK government
}

\section{London}

BRITISH safety limits for the concentration of radon gas in houses are too high and government proposals for financial help to those at risk are "penny-pinching and restrictive", according to the Institution of Environmental Health Officers (IEHO). The institution is the professional organization of environmental safety officers employed by local governments. Its criticisms of government policy appear in a report published two weeks ago.

The key recommendation is that the radon dose at which remedial action is considered to be necessary should be

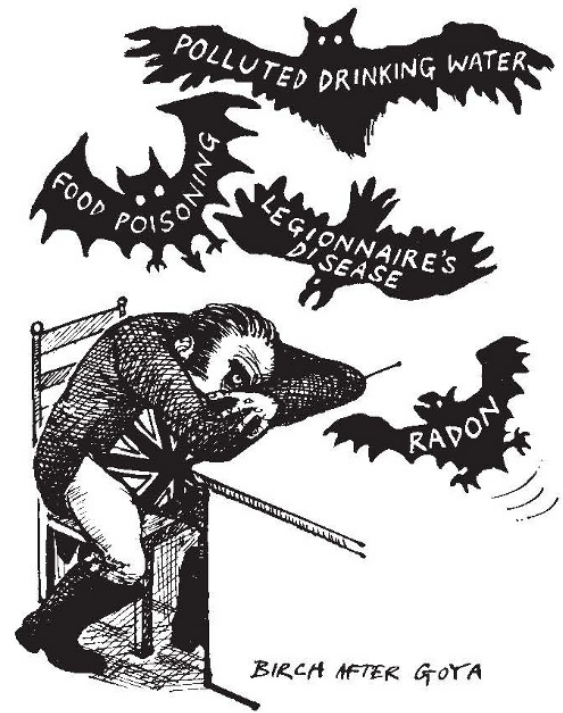

halved, from 400 to 200 becquerels per $\mathrm{m}^{3}$. This concentration was fixed two years ago by the National Radiological Protection Board (NRPB), when it was estimated that the lifetime risk of lung cancer after chronic exposure to $400 \mathrm{~Bq}$ per $\mathrm{m}^{3}$ would be between 2.0 and 2.5 per cent .

The NRPB now estimates the lifetime risk to be 5 per cent, and the environmental health officers say that, as a result, the action level should be halved. The NRPB is now reviewing its safety levels. But Michael O'Riordan of the board says the level will not automatically be halved: the cost of taking remedial action and the available technology will be taken into consideration before a decision is made.

Only in the United States is the action level lower than in Britain: the Environmental Protection Agency (EPA) recommends an action level of $150 \mathrm{~Bq}$ per $\mathrm{m}^{3}$. The agency would like this to be reduced by a factor of 10 , at which point the radon concentrations indoors would be equivalent to those outdoors. But in practice it may only be possible to halve the present action level, says a spokesman. About 8 million homes, 10 per cent of the US total, are estimated to have concentrations of radon above the action level. The most common way of tackling the problem is to "poke a hole in the floor of your basement, put a pipe in, run it through the ceiling and put a fan on the top", according to an EPA spokesman. This can cost between $\$ 200$ and $\$ 1,500$. The EPA is carrying out a survey to find out how many take the necessary action.

In the European Communities, no country other than Britain has any safety levels for radon concentration in the home. But the European Commission is considering recommending that member countries adopt the British standards. Sweden and Finland, the only other European countries with safety levels, set the action level at $800 \mathrm{~Bq}$ per $\mathrm{m}^{3}$.
The IEHO report puts the number of houses in Britain with radon levels above the present action level at 50,000, which is also twice the number estimated by NRPB. As well as the halving of the action level for which it asks, the institution says that the "priority action" concentration should be reduced from 1,000 to $800 \mathrm{~Bq}$ per $\mathrm{m}^{3}$ and that the "investigation" concentration should be reduced from 200 to $100 \mathrm{~Bq}$ per $\mathrm{m}$

The report is especially critical of a government document giving guidance to local authorities on home improvement grants to those potentially at risk. The government expects most owners to bear the cost of remedial action themselves, but Martin Courtis, the report's author, says that if house owners are not offered a grant of at least 75 per cent of the cost of remedial work, there is little, if any, prospect that the radon problem in Britain will be tackled.

\section{Computer microcode instructions judged within copyright}

\section{Berkeley}

A Californian court last week declared that microcode instructions on microprocessor chips can be protected by copyright. The decision, expected to be a landmark for microprocessor manufacturers, is likely to deter outright copying of microprocessor design.

Although computer programs were added to the US Copyright Act by Congress in 1980 , the status of microcode the set of instructions determining how a processor's components will perform a specific function - was unclear. As with any other program, a variety of instruction sets could be devised to achieve the same goal. Last week's ruling puts microcode "squarely within the definition of "computer program"', and therefore subject to copyright protection.

The ruling also ends a 7-year dispute between Intel Corporation, of California and NEC Ltd, of Japan. Intel claimed that NEC's 'V-series' of microprocessors infringe Intel's copyright of its 8086 and 8088 chips, used in the first generation of IBM personal computers. Although the court upheld Intel's right to copyright the microcode, it nonetheless absolved NEC of having violated that copyright, allowing both sides to claim victory in the case.

Intel and NEC entered into a general patent cross-licensing agreement in 1976 giving each access to the other's patents. The copyright dispute arose after Intel introduced the 8086 and 8088 microprocessors in 1978, and NEC began producing identical copies of the chips under the cross-licensing agreement. Intel objected, arguing that the patent-sharing allowed NEC to produce a chip of similar function, but not to use the copyrighted microcode instructions contained in the chip. The matter was temporarily settled in 1983, when Intel licensed NEC to make the chips. Shortly afterwards, NEC developed its own 'V-series' of comparable microprocessors.

The first trial of the lawsuit was discontinued in 1986, when NEC objected that the judge owned a small amount of Intel stock. The judgement in the second trial, announced last week, declared that microcode can be protected by copyright, but found that NEC's microcode is sufficiently different from Intel's not to be a violation. Intel was also found to have forfeited its copyright by not requiring licensees to place notice of the copyright on their chips. NEC now has 11 per cent of the $\$ 7,000$ million microprocessor market, compared with Intel's 26 per cent share, but NEC officials predict that the court's vindication of its practice will improve its sales.

But Intel is also claiming victory, as the decision is likely to discourage others from copying its microprocessor designs. The loss on the 8086 and 8088 chips is financially unimportant, say company officials, as the 10-year-old chips have been replaced in personal computers by second- and thirdgeneration microprocessors. The 8086 and 8088 chips now account for only 1 per cent of total Intel sales, says company representative Pam Pollace. She also says that the more complex microcode of the second- and third-generation 80286 and 80386 microprocessors will be much more difficult to approximate except by outright copying, which would clearly infringe Intel's copyright.
Marcia Barinaga 